\title{
Concepções de psicólogas/os dos CRAS de Salvador sobre demanda escolar
}

\section{Conceptions of psychologists from CRAS in Salvador about school demands}

\section{Thais Fontes Andrade ${ }^{1}$ (i) Marilda Castelar ${ }^{2}$ (1) Liliane Alves da Luz Teles ${ }^{3}$ (1)}

\begin{abstract}
1Autora para correspondência. Escola Bahiana de Medicina e Saúde Pública (Salvador). Bahia, Brasil. thaisandrade12.1@bahiana.edu.br
\end{abstract}
2,3Escola Bahiana de Medicina e Saúde Pública (Salvador). Bahia, Brasil. lilianeteles@bahiana.edu.br,marildacastelar@bahiana.edu.br

RESUMO | O artigo foca nas concepções de psicólogas/os dos Centros de Referência em Assistência Social de Salvador - Ba que recebem demandas escolares. O estudo faz parte de uma ampla pesquisa de Viégas $(2013 ; 2014 ; 2016)$ que identificou a insuficiência de psicólogas/os atuando no campo da educação e encaminhamentos dirigidos a outros serviços públicos que dispõem de atendimento psicológico. 0 estudo utilizou o método qualitativo, entrevistas semiestruturadas com seis profissionais de psicologia que atuam nos CRAS. As entrevistas foram gravadas em áudio, transcritas e analisadas através da articulação de seus conteúdos com os estudos da educação e a construção do espaço das/os psicólogas/os na assistência social considerando as questões envolvidas nessa política pública. Os resultados apontam a necessidade de ampliação das concepções/visões dos profissionais, da construção de novas referências técnicas e o desenvolvimento de ideias, políticas e estratégias para atuação frente a essas demandas. Tais mudanças nas concepções podem promover melhorias nas suas práticas no atendimento de queixas encaminhadas pelas escolas.

PALAVRAS-CHAVE: Educação. Psicologia. Assistência Social. Fracasso escolar.

\begin{abstract}
The article focuses on the conceptions of psychologists from the Reference Centers in Social Assistance (Centros de Referência em Assistência Social - CRAS) in Salvador, state of Bahia, who receive school demands. The study is part of an extensive research by Viégas $(2013 ; 2014 ; 2016)$ that identified the insufficiency of psychologists working in the field of education and referrals directed to other public services that have psychological assistance. The study used the qualitative method, semi-structured interviews with six psychology professionals who work at CRAS. The interviews were audio-recorded, transcribed and analyzed through the articulation of their contents with education studies and the construction of the psychologists' space in social assistance, considering the issues involved in this public policy. The results also point a clear need to expand the conceptions / views of professionals, the construction of new technical references and the development of ideas, policies and strategies to act in the face of these demands. Such changes in conceptions can promote improvements in their practices in handling complaints submitted by schools.
\end{abstract}

KEYWORDS: Education. Psychology. Social Assistance. School Failure. 


\section{Introdução}

Este trabalho foi originado de um desdobramento da pesquisa interinstitucional "Atuação das/os psicólogas/os nos Serviços Públicos de Assistência Social e Saúde frente à demanda escolar na Bahia: concepções, práticas e inovações", desenvolvida entre 2013 e 2016 foi coordenada pela Profa. Dra. Lygia Viégas (FACED - UFBA). Participaram da pesquisa duas instituições de ensino públicas (Universidade Federal da Bahia e a Universidade do Estado da Bahia) e duas instituições privadas (Escola Bahiana de Medicina e Saúde Pública e Faculdade São Bento da Bahia) por meio de seus docentes e alunos de Iniciação à Pesquisa do Curso de Psicologia e da Educação.

A pesquisa recebeu financiamento da Fundação de Amparo à Pesquisa do Estado da Bahia (Edital $n^{\circ}$ 011/2013) com objetivo de fazer um levantamento dos psicólogos que atendem demandas escolares em todo o Estado nos serviços públicos citados. Tinha como objetivo: identificar e analisar concepções e práticas desenvolvidas pelos psicólogos que atuam nos serviços públicos de Assistência Social e Saúde na Bahia frente às queixas escolares, tendo como destaque os Centros de Referência em Assistência Social (CRAS) e Centros de Atenção Psicossocial (CAPS).

Embora se destaque nesta pesquisa equipamentos que fazem parte de políticas públicas heterogêneas, sendo o primeiro, pertencente ao Sistema Único de Assistência Social (SUAS) e, o segundo, do Sistema Único de Saúde (SUS), e que, portanto, conservam suas particularidades, a pesquisa de Viégas e colaboradores $(2013 ; 2016)$ indicou serem estes os principais serviços pelos quais o encaminhamento de demandas escolares estava se concentrando, uma vez que, há um número bastante reduzido de psicólogas/os na Rede Pública de Educação e Rede Privada. Desse modo, as queixas escolares comparecem de forma bastante significativa nos CRAS e CAPS, pois há a presença da/o psicóloga/o como parte da equipe multiprofissional destes serviços, não raramente, são os únicos profissionais disponíveis na rede pública de pequenos municípios da Bahia. Vale destacar que, recentemente, foi aprovada a Lei 13.935/ 2019 que dispõe sobre serviços de Psicologia e de Serviço Social nas Redes Públicas de Educação Básica compondo equipes multiprofissionais, que deverão desenvolver ações para melhoria da qualidade da relação ensino e aprendizagem.
A pesquisa foi desenvolvida e realizada em etapas, que incluiu o mapeamento das profissionais em todo o Estado, o levantamento dessas demandas e, posteriormente, as concepções e práticas desenvolvidas. Para o presente trabalho, será foco aprofundar a discussão sobre as concepções de psicólogas/os dos Centros de Referência em Assistência Social de Salvador-Ba, como entendem e atendem à demanda escolar no seu ambiente de trabalho.

A Política de Assistência Social se expandiu a partir da implementação do SUAS. Com a consolidação dos equipamentos dessa política, especialmente os Centros de Referência em Assistência Social, houve uma expansão também do campo de atuação profissional da/o psicóloga/o, sendo este parte da equipe mínima de referência para o serviço. Este crescimento produziu a necessidade de repensar sua função e papel social para atender as exigências dessa demanda que lida cotidianamente com a desigualdade social e a garantia de Direitos Sociais. Um elemento importante a ser considerado diz respeito ao fato de que, a política do SUAS é intermediária às demais, ou seja, sua funcionalidade está voltada ao não cumprimento e efetivação da integralidade, universalidade e equanimidade da Proteção e Seguridade Social. Portanto, nos cabe pensar a articulação entre a Política de Educação e Assistência Social no trabalho da/o psicóloga/o.

Dentre as exigências imposta para a inserção profissional, foi fundamental reconhecer a construção de referências e diretrizes que orientam a política, bem como, construir normativas condizentes com a demanda social para a profissão de psicóloga/o. Desse modo, sendo uma política recente, bem como ainda tem se constituído a identidade do profissional de Psicologia neste campo novo de atuação, entendemos ser profícua a análise de concepções que respaldam o trabalho da/o psicóloga/o como uma contribuição para repensar seu papel frente às demandas escolares que têm chegado aos CRAS de Salvador-Ba. Pretendemos trazer neste texto questões centrais que envolvem a compreensão do encaminhamento de queixas escolares a estes profissionais, levando em consideração aspectos do sistema educacional num contexto perpassado por desigualdade e exclusão de direitos. 


\section{Papel da Psicologia frente à demanda escolar}

O termo desigualdade social refere ao estado de grande disparidade entre pessoas, uma real situação de desequilíbrio produzido histórica e politicamente. A desigualdade e exclusão social não estão exclusivamente ligadas às disparidades econômicas, apenas ligada a renda, e sim a uma condição política, fruto das forças políticas e econômicas que impetram sob as políticas públicas e os direitos sociais (Gonçalves Filho, 2007). Sua discussão envolve aspectos relacionados à igualdade de direitos, inclusive os de possuir posicionamentos a respeito da realidade.

A autora Maria Helena Souza Patto (2015), autora de referência do nosso estudo para compreender a relação entre Psicologia e Educação, produziu uma crítica fundamental para a compreensão do fracasso escolar a partir da compreensão desse fenômeno como estrutural, perpetrado por um projeto de sociedade capitalista. A autora entende que o fracasso escolar é um problema histórico de um processo de construção do sistema escolar brasileiro marcado por desigualdade (Patto, 2015). As demandas escolares, relacionadas ao aproveitamento do ensino e as dificuldades nesse contexto, tem sido explicados como uma questão ligada ao indivíduo que "não aprende ou não se comporta" (Patto, 2015).

Explicações deterministas, reducionistas e naturalistas sustentaram preconceitos e estereótipos produzidos no bojo da cientificidade. A Psicologia ocupou importante papel na leitura do fenômeno, ao partir do pressuposto de que a "criança problema" não conseguia adaptar-se à escola, por serem originadas de ambientes precários, cujas famílias pobres eram tratadas como desestruturadas (Patto, 2015) ou os professores acusados de descompromissados ou incompetentes (Souza, 2006). Concepções que ora reduzem ao indivíduo, ora ao seu "meio" e que mantém concepções que desconsideram o fracasso escolar como uma produção histórica, social e política na manutenção de um sistema que prevê em sua estrutura, a exclusão e a seletividade. Discursos ideológicos que condicionam a mobilidade social na perspectiva da meritocracia como fundamento, sob ponto de vista de um ideal liberal, cuja estrutura piramidal impôs à escola a função de "reguladora desse tráfego" (Patto, 2015).
A autora, embora não se paute numa perspectiva reprodutivista, discutiu como os sistemas de ensino estão a serviço da estratificação social. Sua obra elucida importantes análises históricas a respeito do fracasso escolar, considerando a participação do próprio sistema escolar na produção desse acontecimento e o papel da Psicologia na manutenção do status quo. Um campo de conhecimentos que se fundamentou a partir da perspectiva de objetificação, mensuração, seleção e adaptação das subjetividades humanas, contribuiu para consolidação de uma visão de mundo que produziu importantes efeitos nas políticas educacionais.

As críticas feitas por Patto (2015) trouxeram como consequência um movimento no interior da própria Psicologia repensando a visão reducionista e simplificadora do fracasso escolar, que, através de explicações medicalizantes, retroalimentam uma engrenagem social sustentada pela subordinação, discriminação e subalternidade presentes no modo de funcionamento capitalista. Entendemos por medicalização um processo em que:

As questões da vida social, sempre complexas, multifatoriais e marcadas pela cultura e pelo tempo histórico, são reduzidas à lógica médica, vinculando aquilo que não está adequado às normas sociais a uma suposta causalidade orgânica, expressa no adoecimento do indivíduo (Fórum sobre medicalização da educação e da sociedade, 2012).

Das críticas à Psicologia Escolar, um grupo de pesquisadores iniciou um movimento na direção da construção da Psicologia Escolar em uma Perspectiva Crítica. Esse movimento reuniu pesquisadores de diferentes perspectivas teóricas que não poderiam mais desconsiderar as produções elaboradas e as críticas feitas ao papel da escola e da Psicologia na conjuntura social.

Sem a pretensão de desvalorizar o papel da escola na sociedade, os autores voltaram seu olhar para repensar o papel que a educação escolar tem desempenhado historicamente. $\mathrm{O}$ acesso à escola ainda não está plenamente democratizado, e mesmo aqueles que têm conseguido se matricular, a participação mais ampla na educação, consideração a aprendizagem dos conteúdos escolares e o desenvolvimento criativo e coletivo dos processos de construção de sentidos sobre a vida tem sido esvaziados, desconsiderando a realidade social. 
Atentos a esse desafio, foi necessário construir referências coerentes com a compreensão do fracasso escolar como um fenômeno multideterminado que não reforçassem um modelo tradicional de atuação, que possa envolver importantes questões acerca das contradições, conflitos e paradoxos do sistema social vigente. É necessário questionar junto com a escola o seu sentido, mas principalmente um exercício de autocrítica da profissão, para quem e como se engendram as práticas constituídas neste cotidiano.

As práticas coletivas de produção de subjetividade se apresentam para nós como estratégia de interferência no processo educativo, levando em conta que

os sujeitos, quando mobilizados, são capazes de transformar realidades, transformando-se a si próprios nesse mesmo processo (CFP, 2013, p.44)

Nesta direção, consideramos relevante citar as Referências Técnicas para Atuação de Psicólogas (os) na Educação Básica publicada em 2013 e revisada em 2019 (CFP, 2019), que define o fracasso escolar como objeto da Psicologia, cujas teorias precisam considerar o instituído e o institucionalizado nas práticas de atenção e cuidado, considerando as redes interna e externa que os tensionam. Esta Referência foi desenvolvida por meio do Centro de Referência Técnica em Psicologia e Políticas Públicas (CREPOP), produzindo informação qualificada para que o Sistema Conselhos pudesse implementar políticas para a orientação da atuação profissional no serviço público. O documento se baseia em dois grandes movimentos: "o da sociedade brasileira nos rumos do processo de democratização e da própria Psicologia em busca de referenciais ético-políticos, em defesa de uma Educação pública, gratuita, laica e de qualidade para todos e todas" (CFP, 2019, p. 24).

Dentre as possibilidades de atuação, As Referências destacam que é fundamental reconhecer o trabaIho da/o psicóloga/o como aquele que se coloca em parceria, ao lado da equipe pedagógica contribuindo para a construção participativa e democrática do Projeto Político Pedagógico.

Sendo o foco da instituição escolar o processo de ensino e aprendizagem, a contribuição da psicologia neste campo precisa considerar as condições histórico-sociais, buscando o enfrentamento de situações naturalizadas no contexto escolar, explicações reducionistas que culpabilizam os indivíduos pelas dificuldades vivenciadas neste processo. Nas Referências, esse trecho reúne uma compreensão sobre o papel da/o psicóloga/o, cujo entendemos ter afinidade com a perspectiva crítica, dialogando com a proposta do CRAS no fortalecimento dos vínculos e do empoderamento das situações de conflito:

A luta da (o) psicóloga (o) é a de sustentar um campo de indagações que dê tempo para que os educadores possam se deslocar também dos seus lugares marcados na dicotomia ensinar $x$ aprender, na sensação de impotência frente às condições, na desistência de transformações do cotidiano. Para isso é fundamental contribuir para a produção de novas perguntas que problematizem as relações que focam as explicações no indivíduo, considerado causas "em si" das questões geradoras de sofrimento, em que não há nada a fazer. Logo, perguntar sobre as situações, as circunstâncias, os valores, as condições histórico-sociais, as práticas

que constroem o dia a dia é o que movimenta o trabalho, potencializando uma rede partilhada de ações/reflexões. Nesse movimento, profissionais de várias áreas, com diversos conhecimentos das ciências produzidas pelos homens são convidados a participar dessa reflexão e elaborar medidas que contribuam para o enfrentamento das questões postas no cotidiano da escola. (CFP, 2019, p. 34).

As Referências não apenas oferecem diretrizes para a atuação profissional, mas indicam um importante avanço na direção tanto do atendimento quanto do entendimento do que são as demandas escolares a partir do acúmulo de conhecimentos produzidos na área. Desse modo, entendemos ser importante compreender se estas discussões têm comparecido aos profissionais que atendem esta demandam, não apenas aos psicólogos escolares e educacionais. Portanto, entendemos ser relevante este trabalho, para analisar as concepções das/os profissionais psicólogas/os que têm recebido nos CRAS o encaminhamento de queixas escolares, entendendo que são reflexões sobre suas práticas interventivas, produtos de uma posição dialética da/o profissional ao influenciar e ser influenciado/a no contexto. Para tal, buscamos elucidar alguns elementos que estão relacionados a atuação das/os psicólogas/os nos CRAS.

\section{Atuação dos psicólogos nos CRAS diante das de- mandas escolares}

A Constituição de 1988 foi um marco importante de início de mudanças no cenário da assistência social. Esta trouxe implicações fundamentais, uma vez que colocou as ações desse campo articuladas 
com a saúde e previdência, constituindo o Sistema Brasileiro de Seguridade Social, este sendo reconhecido como política pública em 1993, com a vigência da Lei Orgânica de Assistência Social (LOAS), que visa a garantia dos direitos e promoção da cidadania a diversos segmentos populacionais e preconiza proteção social a todos que necessitam (CFP, 2007).

A Política Nacional de Assistência Social (PNAS) aprovada em 2004, é operacionalizada através do Sistema Único de Assistência Social (SUAS), tendo em 2005 a construção do projeto político para assistência inspirado na lógica do SUS. Essa proposta visou à radicalização dos modos de gestão e financiamento das ofertas institucionais no campo da assistência social, o que possibilitou o início de uma ruptura com os modelos assistencialistas historicamente impregnados (CFP, 2007). O SUAS realiza suas intervenções a partir de duas formas de proteção social, sendo elas: a proteção social básica e a proteção social especial. Para este artigo, falaremos somente sobre a proteção social básica, que propõe prevenir situações de risco por meio do desenvolvimento de potencialidades e aquisições, e o fortalecimento de vínculos familiares e comunitários.

O principal responsável pela organização e oferta de serviços da proteção social básica do SUAS nas áreas de vulnerabilidade e riscos sociais presente na maioria dos municípios brasileiros chama-se Centro de Referência de Assistência Social (CRAS). Esse equipamento é um aparelho público estatal e se caracteriza como a principal porta de entrada do SUAS. As principais funções dos CRAS são: promover a articulação intersetorial e a busca ativa, ofertar os serviços continuados de proteção, envolvendo: famílias, grupos e indivíduos, realizando atividades: socioeducativas, geracionais, intergeracionais, sócio comunitário; realizar a distribuição dos benefícios e o desenvolvimento dos programas e projetos de capacitação e promoção da inserção produtiva, promoção da inclusão produtiva para beneficiários do Programa Bolsa Família (PBF) e do Benefício de Prestação Continuada, de enfrentamento à pobreza, de enfrentamento à fome, grupos de produção e economia solidária; geração de trabalho e renda (CFP, 2007).

Os profissionais de psicologia fazem parte da equipe mínima dos CRAS, desde o início da implantação do sistema SUAS, portanto, considera-se fundamental refletir a construção do espaço dessa profissão nesse equipamento. Nessa inclusão, as/os psicólogas/ os foram convidadas/os a trabalhar pela superação da desigualdade social, visto que esta pode ser geradora ou agravante de sofrimento psíquico. Diante dessa convocação para atuar nos equipamentos públicos, mas especificamente nos CRAS, os profissionais confrontam-se com questões sociais que, até o momento, eram ignoradas (Santos, Roesch \& Cruz, 2014). Torna-se necessário que as/os psicólogas/os trabalhem na compreensão desse novo espaço de atuação, analisem as questões históricas, sociais, culturais e políticas envolvidas neste e nas suas demandas. Nesse campo, podem ser desenvolvidas diferentes práticas e atividades psicológicas em espaços institucionais e comunitários.

É importante para as/os psicólogas/os que atuam no CRAS compreenderem o papel ativo do indivíduo e a influência das relações sociais, valores e conhecimentos culturais na sua formação. As práticas desses profissionais também visam: compreender e acompanhar os movimentos de construção subjetiva de pessoas, grupos comunitários e famílias, atentando para a articulação desses processos com as vivências e as práticas sociais presentes no contexto sócio comunitário e familiar. No atendimento, deve-se desenvolver as ações de acolhida, orientações, visitas e entrevistas domiciliares, articulações institucionais dentro e fora do território de abrangência do CRAS, atividades socioeducativas e de convívio, facilitação de grupos, estimulando processos contextualizados (CFP, 2007).

Os CRAS por conta do Decreto n ${ }^{\circ} 5.209$, de 17 de setembro de 2004 (Brasil, 2004), que traz a frequência das crianças na escola como uma condicionalidade para o recebimento do Programa Bolsa Família (PBF), que possui a função de contribuir para o combate à pobreza e a desigualdade no Brasil. O PBF contempla três eixos principais: o complemento de renda, o acesso aos direitos (a família deve cumprir algumas condicionalidades, que visam a chegada da garantia de direitos sociais básicos cheguem a população em situação de pobreza, tais como o acesso à educação, saúde e a assistência social) e a articulação com outras ações de cunho social (MDS, 2004). Uma das razões para encontrar nesse equipamento questões do sistema educacional, é discutido por Saraiva (2018) a partir da experiência de grupos multifamiliares realizados em um Centro de Referência de Assistência Social (CRAS). Geralmente, a questão da educação comparece aos CRAS em função do descumprimento da condicionalidade (referente à exigência de 
frequência escolar mínima de $85 \%$ para crianças e adolescentes entre 6 e 15 anos e $75 \%$ para adolescentes entre 16 e 17 anos).

O autor destaca que, os responsáveis pelo cadastro das famílias passavam por atendimentos individuais, cuja ação era focada na sanção recebida em decorrência de supostos problemas familiares que fariam com que seus filhos faltassem à escola. Em consonância com o discurso da Política do Programa Bolsa Família, reforçava-se a importância da escola para o rompimento do ciclo da pobreza entre gerações, dizendo-se que deveriam fazer com que a criança voltasse à escola e fazendo encaminhamentos necessários, para os órgãos gestores da Educação e Conselho Tutelar. Apesar de previsto, quase nenhum recurso para a reversão da sanção recebida era apresentado (Saraiva, 2018).

No trabalho, Saraiva (2018) destacou que ao longo dos encontros realizados com os grupos entendeu-se não haver questões familiares produzindo baixa frequência escolar. Questões relacionadas a estrutura, assistência e funcionamento escolar, tais como: dificuldades de deslocamento até a escola, devido à falta de transporte escolar e que se agravava em dias de chuva; a dificuldade em comprar todo o material escolar e uniforme e em pagar taxas exigidas por algumas escolas, mesmo públicas, o que acabava adiando o início do ano letivo para aqueles que não conseguissem arcar com todas as exigências; a falta de vagas no início do ano letivo ou para aqueles que haviam se mudado para a cidade em outros período; dentre outros, foram observados.

Ainda haja clara articulação entre a função do CRAS diante de demandas escolares, imposta na condicionalidade do PBF, há ainda o encaminhamento de queixas escolares para atendimento psicológico nestas unidades na Bahia, como destaca a pesquisa de Viégas (2016). No entanto, não é raro vermos a unidade escolar sendo foco de ações de cunho intersetorial cuja finalidade está voltada para orientação das crianças e famílias através de palestras, oficinas, reuniões, mas que pouco aborda a questão do fracasso escolar como foco. As atividades de cunho informacional, via de regra, lidam com orientações "socioeducativas" (Oliveira et al., 2014), mas que não levam em conta uma articulação interinstitucional para enfrentamento de um dos grandes desafios para a infância e para a Educação que é o fracasso escolar. Isso se deve ao fato de que o entendimento de demandas escolares são compreendidas pelo viés individual e psicologizante (Viégas, 2016).
Diante da presença das demandas escolares é de extrema importância que os profissionais tenham conhecimento a respeito das queixas escolares e dos aspectos envolvidos nesta. Para que sejam realizadas intervenções que não sejam apenas focadas no "transtorno", dificuldade, problema, e sim que consideram o sujeito inserido no ambiente social (CFP, 2007). Para isto é preciso identificar quais são as concepções dos profissionais em relação às demandas escolares, visto que estas servem também como uma base para as suas práticas.

\section{Métodos}

A presente pesquisa possui caráter qualitativo, de cunho empírico e descritivo. Inicialmente foi preciso realizar o mapeamento dos CRAS de Salvador, e identificar os profissionais de psicologia que atuassem nesses. Foram localizados 24 Centros de Referência em Assistência Social em funcionamento, tendo em todos os equipamentos a presença de profissionais de psicologia trabalhando na ocasião da coleta de dados, ocorrida de fevereiro a março de 2016.

Os contatos iniciais com as/os psicólogas/os se deram através de uma profissional de psicologia que atua em um dos CRAS de Salvador, fator determinante e que possibilitou o acesso às/aos psicólogas/os que se encontravam atuando na ocasião da realização das entrevistas. Destacamos que nossa pesquisa foi submetida e obteve aprovação no Comitê de Ética em Pesquisa, conforme parecer conforme parecer N352. 996 - 07/08/2013, CAAE 13824913.7.1001.5531, relativo à Resolução no. 510/16, do Conselho Nacional de Saúde, que regula a avaliação da ética em pesquisa nas Ciências Humanas e Sociais.

De acordo com Meihy e Ribeiro (2011) o processo de encaminhamento de uma pessoa para outra que possa participar da entrevista está previsto nos procedimentos da história oral. Assim sendo, obteve-se o acesso aos contatos telefônicos desses profissionais. Durante o contato telefônico, mantido com 15 profissionais, todas foram convidadas(os) a participar da entrevista. Dessas foram entrevistados quatro psicólogas e dois psicólogos, todos concordaram em assinar o Termo de Consentimento Livre Esclarecido para responderem a um questionário prévio para a pesquisa mais ampla, deram seu consentimento oral nas gravações para o uso e publicação do seu conteúdo 
com preservação de suas identidades. As seis entrevistas foram semiestruturadas, gravadas em áudio, transcritas e conferidas. Para efeito de preservação das identidades foram utilizados apenas números para identificar cada participante de E1 a E6, de acordo com a ordem da realização das entrevistas.

Para este presente artigo foi realizada a análise de todo o conteúdo com a finalidade de compreender a sua concepção de demanda escolar para estes profissionais. A partir das leituras flutuantes, buscamos contemplar as concepções sobre demandas escolares das/os participantes, fundamentadas na formação acadêmica obtida, no contato com a realidade concreta e nas consequências de suas concepções refletidas nas práticas descritas. Alguns trechos serão destacados para dar visibilidade a análise elencada, sem a pretensão de desconsiderar as singularidades dos sujeitos entrevistados.

\section{Resultados e Discussão}

Os participantes atuavam no CRAS no período de 3 a 10 meses. Devido a rotatividade de profissionais nesse espaço, por questões políticas, estruturais e organizacionais, teve-se uma grande dificuldade em encontrar profissionais que estavam trabalhando por mais de 12 meses no serviço, e por conta disso não foi possível identificar psicólogos com grande período de atuação nesse equipamento.

Os psicólogos entrevistados tinham entre 23 e 54 anos de idade, sendo quatro psicólogas e dois psicólogos. Apenas um psicólogo identificou-se como negro, todos os outros, como brancos; possuíam entre nove meses a três anos de tempo de profissão, muitos tendo o serviço público como o primeiro emprego. Dados que condizem com o perfil e a autodeclaração mapeada na publicação "Quem é a psicóloga brasileira" (CFP, 2013) e que levanta uma série de questionamentos tanto do ponto de vista do público que tem acesso a formação em Psicologia, quanto às questões de identidade racial dessas profissionais, ao acesso ao mercado de trabaIho e ao crescimento exponencial de cursos e quantitativo de profissionais recém formados que ingressam nas políticas públicas com vínculos precarizados.

A concepção das/o profissionais que atuam nos CRAS, a respeito das demandas escolares, traz a forma como estes compreendem e analisam essa demanda, e de qual maneira esta pode interferir nas suas práticas. Diante disso, serão apresentados a seguir os entendimentos das/os psicólogas/os sobre a demanda escolar e as diversas críticas produzidas por estes em relação ao sistema educacional.

Encontra-se nos relatos de alguns desses profissionais a referência quanto ao entendimento das demandas como oriundas das dificuldades vivenciadas no processo de escolarização, mas que ainda mantém uma visão focada nos indivíduos, como resultado de uma integração entre a escola, a família e o aluno, mas que não amplia a concepção para o fenômeno que envolve questões macroestruturais:

Bom, as demandas escolares acho que vem do próprio processo de ensino-aprendizado, do próprio processo da escola mesmo, não está na questão só professor, na questão só aluno, na questão só pais, mais nesse enredo que é família-escola-criança. Que nesse processo vão sendo construído as demandas e as queixas, então vejo muito por essa via de que não está na criança, não está especificamente nos pais, não está especificamente na escola, mas em sim em todo um contexto. (E6)

Eu acho que é um tema amplo, em relação a questão da escola, eu acho que a escola é uma instituição social, é um local também de contribuição do sistema de educação, um local de ensino e aprendizagem. Mas, eu como profissional acho que só a escola não é suficiente, precisa muito da contribuição da família. Eu acho que a soma de todos os âmbitos sociais na constituição da educação dessa criança. (E5)

Podemos perceber nesta primeira fala que, mesmo não entrando na perspectiva de culpabilização de um seguimento, nem trazem elementos de compreensão do fenômeno histórico, político, social. Os participantes, de uma maneira geral, não contextualizam o que compreendem por processo de ensino e aprendizagem, e, embora apontem a escola como uma instituição social, o que parece um avanço, entretanto a problematização desta em sua história e constituição é frágil. Com isso, consideramos que é necessária a articulação entre família - escola - aluno, mas destacamos a importância de entender esse tripé a partir da noção da atuação política, para além da questão pedagógica, numa participação ativa no sentido amplo da educação sem recair numa concepção de parceria que acaba se limitando ao cumprimento das tarefas escolares. Do mesmo modo, vale considerar que, isso inclui um repensar sobre as desigualdades que se ensejam na educação. 
Pesquisa feita por Tameirão (2018), que teve por objetivo principal investigar e analisar os casos de fracasso escolar encaminhados à política de assistência social no município de Diamantina-MG, dentro do contexto de um Centro de Referência da Assistência Social - CRAS Regional II, nos anos de 2016 e 2017 aponta que os sujeitos relacionados ao fracasso escolar e encaminhados ao CRAS, em sua maioria, são do sexo masculino, negros, provenientes de bairros periféricos, compõem o núcleo familiar de famílias que em sua maioria recebem o benefício de transferência de renda do governo federal. Ressalta em suas conclusões que há necessidade de melhor articulação, visando alcançar de forma conjunta e continua$\mathrm{da}$, resultados que possam servir de solução para a minimização de casos de fracasso escolar atribuídos a crianças e adolescentes (Tameirão, 2018). Neste sentido, é necessária uma ruptura na forma de compreender a gênese do fracasso escolar, o que leva a uma perspectiva individualizante com foco do sujeito no meio (entendida como as relações diretas entre seu núcleo familiar e professores).

Patto (2015) ao criticar o olhar da psicologia, contribuiu para repensar seu papel, analisando o contexto que passou a ser algo mais presente nos estudos e práticas das/os psicólogas. É importante considerar que não foi exposta pelos participantes a questão da desigualdade no âmbito educacional, frente à acessibilidade, continuidade dos alunos nas escolas e a qualidade de ensino. Essas questões são fundamentais ao lidar com uma população oriunda de situações de pobreza.

Ainda foram encontrados nos discursos que focalizam o papel do professor para justificar as dificuldades presentes, as demandas e até mesmo o fracasso:

(...) O professor, tanto que eu cheguei a conhecer na mesma escola conhece professor que oferece escuta ao aluno, dentro da escola vir professor que tem uma linha de comunicação fluente, fácil, acessível com o aluno e com certeza esse professor, os alunos desse professor dificilmente eles vão estar aparecendo no

CRAS. (E3)

Olha, é muito complexo. Primeiro porque assim os professores eles também não têm esse preparo, este estímulo. Então assim, é um professor que muitas vezes deveria esta responsável por estar lidando com aquelas queixas, deveria ter recursos para lidar com aquelas situações e ele acaba transferindo para outro profissional, outro órgão. (E4)
Os/as psicólogos/as versam sobre os professores como profissionais despreparados para lidar com as demandas do meio escolar. Acreditam também que a forma como esses professores trabalham pode interferir na quantidade dessas demandas. Souza (2006) problematizou tal perspectiva, uma visão que desconsidera os desafios vivenciados pelos educadores, uma realidade marcada pela precarização, burocratização e massificação do trabalho docente, cujas condições objetivas não atendem às necessidades pedagógicas. Nota-se a perspectiva de que professores são percebidos como incapacitados para compreenderem as dificuldades dos alunos e realizar encaminhamentos "assertivos".

Foi o que eu falei da capacitação profissional, porque um professor se ele for psicopedagogo, ele vai ter um parâmetro para poder falar aquilo, mas, se ele nunca estudou aquilo, ele só ouviu falar, ele não parou para se concentrar, e ele apenas não tem paciência com aquela criança. Ai manda, eles jogam a responsabilidade sabe? Eles transferem

a responsabilidade, eles não tentam resolver o problema, eles transferem a responsabilidade, então, eu acho que além de ser uma coisa tratada sem muita seriedade. (E2)

O relato exprime uma concepção reducionista do discurso da incompetência docente. Como consequência, pode-se concluir que para os entrevistados, a demanda chega ao CRAS em virtude do descompromisso ou falta de formação do professor, sobrecarregando as demandas nesse equipamento e com isso responsabilizando o próprio psicólogo do seu papel.

Embora críticas importantes à visão reducionista sobre as demandas escolares tenham se consolidado, isso não significou uma problematização ampliada que se contraponha a esse modelo ainda hegemônico que tendem a um viés medicalizante. Os professores, na concepção dos entrevistados, ocupam o lugar de responsável pelo fracasso, ainda que vitimados por serem oriundos de um Estado que não se responsabiliza por investimentos efetivos na Educação e valorização do corpo docente.

Para explicaçõessimplistas, surgem soluções rasasque não respondem a complexidade do caráter multifacetado que produz esses encaminhamentos. Podemos vislumbrar que as/os entrevistadas/os acreditam na necessidade da/o psicóloga/o nas escolas, como se a presença desse profissional correspondesse a uma 
triagem e fosse suficiente para lidar com as dificuldades que produzem demandas de atendimento:

Olha! Vou fazer uma crítica em relação a demanda escolar, porque assim, eu vejo que há uma necessidade extrema de um psicólogo em todas as escolas, o psicólogo ele precisa, o governo precisa colocar um psicólogo para acompanhar essas crianças dentro da escola, porque assim, os professores eles não têm, a maioria deles não tem o olhar, para fazer esse diagnóstico para encaminhar, porque assim todo mundo que encaminha, todo mundo, a criança ou é hiperativa ou tem déficit de atenção.(E2)

A presença do psicólogo no ambiente escolar precisa ser vista de forma ampliada, não somente como aquele que está presente para realizar diagnóstico e encaminhar, e sim para atuar de forma ativa, participando das atividades da escola, compondo uma equipe que busca coletivamente enfrentar os desafios vivenciados. Embora na Bahia a presença de psicólogas da rede de ensino seja muito restrita, experiências em todo o país e que são difundidas na literatura apontam que, é possível identificar a tendência em compreender como doença aqueles que vivenciam dificuldades no processo de escolarização, reduzindo o olhar ao indivíduo e adotando explicações organicistas para o fenômeno. Nesta análise, a fala traz um viés dúbio, ao mesmo tempo em que pode ser um questionamento do diagnóstico mal realizado, pode ser entendida também como uma crítica à medicalização do fenômeno.

Além disso, é preconizado pela Política de Assistência Social o fortalecimento das instituições e da comunidade. Nesse sentido a concepção tradicional trazida no relato acima não garante uma atuação condizente com o que fundamenta o papel da Psicologia Escolar e Educacional em uma perspectiva crítica e dos princípios que se baseiam o trabalho da Psicologia no SUAS. A concepção sobre as demandas escolares revela uma complexidade que precisa ser compreendida de forma multifatorial, uma vez que o CRAS tem como finalidade a proteção dos direitos da sociedade, especialmente daqueles considerados mais vulneráveis.

Os resultados apontam que as concepções das/ os profissionais carregam muitas contradições que dizem respeito, não somente a compreensão das demandas escolares, mas também, quanto ao papel do CRAS no fortalecimento da política educacional e em relação ao seu próprio papel, como um profissional que precisa compreender e dialogar com a comunidade atendida no sentido de garantir o acesso a uma educação de qualidade. E necessário romper com o processo de culpabilização dos professores, realizando uma crítica que possibilite situar o papel da educação, da escola e da Psicologia a partir de uma análise sócio-histórica.

\section{Considerações Finais}

A pesquisa trouxe elementos que possibilitaram analisar criticamente concepções contraditórias das/os psicólogas/os. As concepções ainda estão voltadas a uma perspectiva reducionista do fracasso escolar, desconsiderando sua gênese histórica e sua produção como parte de um sistema social. Apontam como solução, a presença de profissionais da psicologia nas escolas, o que denota por um lado, que compreendem tais demandas como oriundas das experiências individuais, subjetivas, de caráter psicológico e não pedagógico, e, por outro, acabam desqualificando a possibilidade da equipe pedagógica lidar com os desafios enfrentados.

Nesta direção, podem reforçar práticas tradicionais que naturalizam os encaminhamentos, uma vez que não há uma reflexão a respeito da exclusão na escola e da escola. Nota-se também a ideia de que as demandas escolares, não são demanda para os CRAS, o que pode produzir uma desresponsabilização diante do fenômeno. Neste jogo de forças, aqueles que estão historicamente vulnerabilizados, podem ficar à deriva dos direitos de garantia à assistência social e à educação.

Diante dos resultados da pesquisa, considera-se relevante realizar um trabalho, que possibilite uma discussão entre os profissionais sobre suas concepções, e aprofundar no sentido de compreender como as práticas profissionais são produzidas a partir de tais concepções, no intuito de alcançar os objetivos pretendidos pelos CRAS, a partir do estabelecido para o papel da/o psicóloga/o nesse equipamento. 


\section{Contribuições das autoras}

Andrade, T. F. participou de todas as etapas da pesquisa sendo responsável pela concepção, desenho, análise, interpretação dos dados e escrita do artigo. Castelar, M. participou da orientação para a concepção, desenho e posteriormente da análise, interpretação dos dados e elaboração final do artigo. Teles, L. A. L. participou da interpretação dos dados e escrita e elaboração final do artigo. Todas as autoras aprovaram a versão final do artigo.

\section{Conflitos de interesses}

Nenhum conflito financeiro, legal ou político envolvendo terceiros (governo, empresas e fundações privadas, etc.) foi declarado para nenhum aspecto do trabalho submetido (incluindo, mas não se limitando a subvenções e financiamentos, participação em conselho consultivo, desenho de estudo, preparação de manuscrito, análise estatística, etc.).

\section{Referências}

Brasil. Ministério do Desenvolvimento Social e Combate à Fome. (2004). Política Nacional de Assistência Social. Brasília: Ministério do Desenvolvimento Social e Combate à Fome. Recuperado de http://www.mds.gov.br/webarquivos/ publicacao/assistencia_social/Normativas/PNAS2004.pdf

Conselho Federal de Psicologia. (2007). Referência técnica para atuação do(a) psicólogo(a) nos CRAS/SUAS. Brasília: Conselho Federal de Psicologia. Recuperado de http:// crepop.pol.org.br/5763_referencias-tecnicas-paraatuacao-doa-psicologoa-no-cras

Conselho Federal de Psicologia. (2013). Quem é a Psicóloga brasileira? Mulher, Psicologia e Trabalho [Internet]. Recuperado de https://site.cfp.org.br/cfp-lancapublicacao-quem-e-a-psicologa-brasileira-mulherpsicologia-e-trabalho/

Conselho Federal de Psicologia. (2019). Referências Técnicas para Atuação de Psicólogas (os) na Educação Básica (2a ed.). Brasília: Conselho Federal de Psicologia. Recuperado de https://site.cfp.org.br/wp-content/uploads/2019/08/ EducacaoBASICA_web.pdf

Fórum sobre medicalização da educação e da sociedade. (2013). Recomendações de práticas não medicalizantes para profissionais e serviços de educação e saúde ( $2^{\mathrm{a}}$ ed. rev.). São Paulo:Autor.

Gonçalves Filho, J. M. (2007). Humilhação social: humilhação política. In B. P. Souza. Orientação à Queixa Escolar (pp.187221). São Paulo: Casa do Psicólogo.
Meihy, J. C. S. B., \& Ribeiro, S. L. S. (2011). Guia prático de história oral: para empresas, universidades, comunidades, famílias. São Paulo: Contexto.

Oliveira I. F., Oliveira, N. L. A., Nascimento, M. N. C., Araújo, R. L., Coelho-Lima, F., \& Amorim, K. M. O. (2014). Atuação dos psicólogos nos CRAS do interior do RN. Psicologia \& Sociedade, 26(spe2), 103-112. Recuperado de https://www.scielo.br/scielo.php?pid=S0102$71822014000600011 \&$ script=sci_abstract\&tlng=pt. doi: 10.1590/S0102-71822014000600011

Patto, M. H. S. (2015). A produção do fracasso escolar: histórias de submissão e rebeldia. São Paulo: Intermeios.

Santos, N. L., Roesch D., \& Cruz L. R. (2014). Vulnerabilidade e risco social: produção de sentidos no campo sócio assistencial. Revista Jovens Pesquisadores, 4(1), 119-27. Recuperado de https://online.unisc.br/seer/index.php/ jovenspesquisadores/article/view/4515. doi: 10.17058/rjp. v4i1.4515

Saraiva, L. F. O. (2018). O atendimento a queixas escolares no CRAS. Psicologia Escolar e Educacional, 22(1), 21517. Recuperado de https://www.scielo.br/pdf/pee/ v22n1/2175-3539-pee-22-01-215. pdf. doi: 10.1590/217535392018011944

Souza, D. T. R. (2006). Formação continuada de professores e fracasso escolar: problematizando o argumento da incompetência. Educação e Pesquisa, 32(3), 477 92. Recuperado de https://www.scielo.br/scielo. php?pid=S1517-97022006000300004\&script=sci_ abstract\&tlng=pt. doi: $10.1590 /$ S1517-97022006000300004

Tameirão, K. C. (2018). Fracasso escolar: casos encaminhados ao CRAS Palha de Diamantina-MG (Dissertação de Mestrado). Universidade Federal dos Vales do Jequitinhonha e Mucuri, Diamantina, MG, Brasil. Recuperado de http:// acervo.ufvjm.edu.br/jspui/handle/1/2131

Viégas, L. S. (2013). A atuação do psicólogo nos serviços públicos de Assistência Social e Saúde frente à demanda escolar na Bahia: concepções, práticas e inovações. Salvador: Mimeo.

Viégas, L. S. (2014). Atuação do psicólogo na rede pública de educação da Bahia. In M. P. R. Souza, S. M. C. Silva, K. Yamamoto. Atuação do psicólogo na educação básica: concepções, práticas e desafios (pp. 99-112). Uberlândia, MG: EDUFU.

Viégas, L. S. (2016). O atendimento à queixa escolar na educação pública baiana. Rev. Entreideias, Salvador, 5(1), 57-72. Recuperado de https://portalseer.ufba.br/index.php/ entreideias/article/view/14464/11023 